
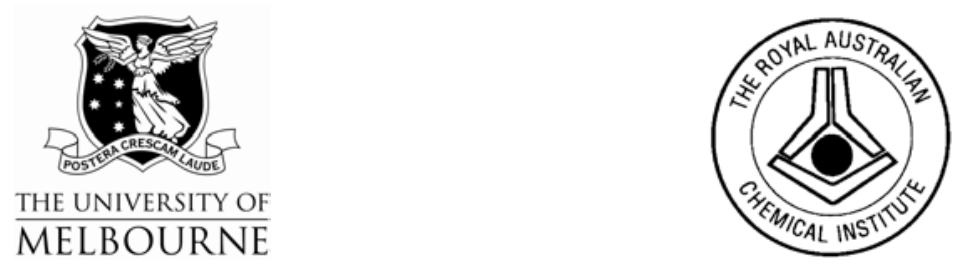

molecules

ISSN 1420-3049

http://www.mdpi.org

\title{
Nitrogen Heterocycles as Building Blocks for New Metallo- supramolecular Architectures
}

\section{Peter J. Steel}

Department of Chemistry, University of Canterbury, Private Bag 4800, Christchurch, New Zealand. Tel. (+64) 3-3642432, Fax (+64) 3-3642110, e-mail peter.steel@canterbury.ac.nz

Received: 4 March 2004 / Accepted: 6 March 2004 / Published: 31 May 2004

\begin{abstract}
The syntheses of representative examples of five classes of new heterocyclic ligands are described. These include N,N'-chelating bis-heterocycles, binucleating ligands, cyclometallated compounds, chiral ligands and a family of polyheteroaryl-linked arenes.
\end{abstract}

Keywords: Heterocyclic ligands, chiral ligands, bridging ligands, cyclometallation.

\section{Introduction}

For many years now, we have been involved in the synthesis of new heterocyclic compounds for use in coordination, organometallic and metallosupramolecular chemistry. In this review the syntheses of representative examples of five different classes of ligands are reviewed. These all incorporate N,N'bidentate coordinating binding domains similar to that found in 2,2'-bipyridine, which has been used as a ligand for well over a century [1] and shown to coordinate to almost any metal in the periodic table [2].

\section{N,N'-Chelating Bis-heterocycles}

Despite the long history of 2,2'-bipyridine in coordination chemistry, only relatively recently has it been recognized that replacement of one, or both, of the pyridine rings with other heterocyclic rings can result in dramatic changes to the physicochemical properties of the resulting complexes [3]. We have synthesized many previously unstudied bis-heterocycles and investigated their coordination 
chemistry. In general the synthetic procedures involve relatively simple reactions in which either two pre-formed rings are coupled by metal-catalyzed couplings or nucleophilic substitution reactions, or alternatively one, or both, of the rings can be generated by ring-forming condensations or cycloadditions. These ligands can be divided into symmetrical and unsymmetrical examples. The syntheses of three representative examples are shown in Scheme 1.

\section{Scheme 1.}
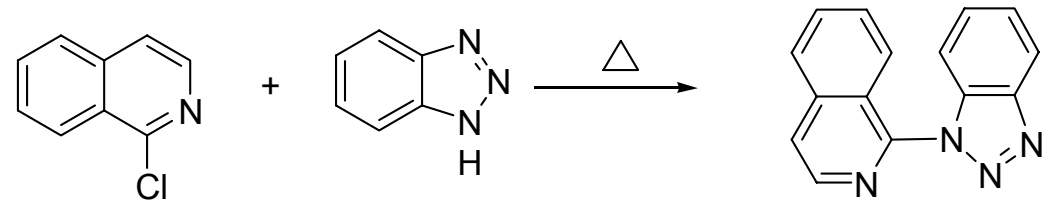

1
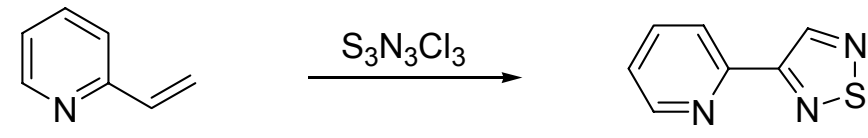

2

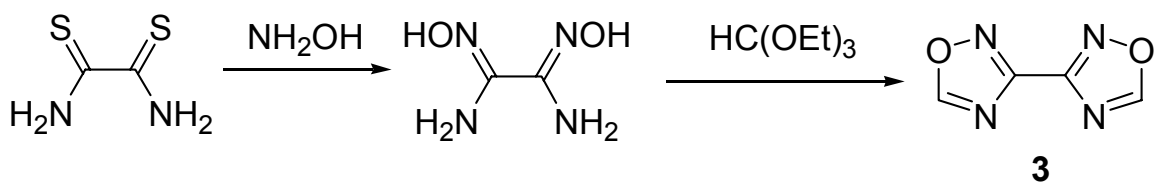

Ligand 1 contains isoquinoline and benzotriazole rings and is readily prepared from 1-chloroisoquinoline and benzotriazole by nucleophilic substitution [4]. Ligand 2, containing pyridine and 1,2,5-thiadiazole rings, is prepared from 2-vinylpyridine by reaction with trithiazyl trichloride [5]. Ligand 3 is a symmetrical 3,3'-bi-1,2,4-oxadiazole and is readily prepared from rubeanic acid by double cyclocondensation of the intermediate oxalamidoxime [5]. Ligands such as these have proved useful for the construction of various mononuclear and multinuclear metal complexes. The incorporation of $\pi$-excessive azole rings into such chelating ligands results in very different properties for the resulting complexes, compared to the $\pi$-deficient azines, such as pyridine. Many of the ligands we have synthesized incorporate heterocyclic rings that have not previously been used as ligands. We have also extended this work to $\mathrm{N}, \mathrm{N}^{\prime}, \mathrm{N}$ "-tridentate ligands, analogous to 2,2',2"-terpyridine.

\section{Binucleating Ligands}

Ligands that have two N,N'-bidentate binding domains are used to bridge two metal centres [6-8]. There is much interest in the nature, and magnitude, of metal-metal interactions in such complexes [9]. We have synthesized a number of such ligands. Scheme 2 shows the syntheses of three representative examples, which bridge two metal centres with progressively increasing metal-metal separations. 


\section{Scheme 2.}<smiles>CCON(CC(=O)c1ccccn1)C(=O)CC(=O)c1ccccn1</smiles>
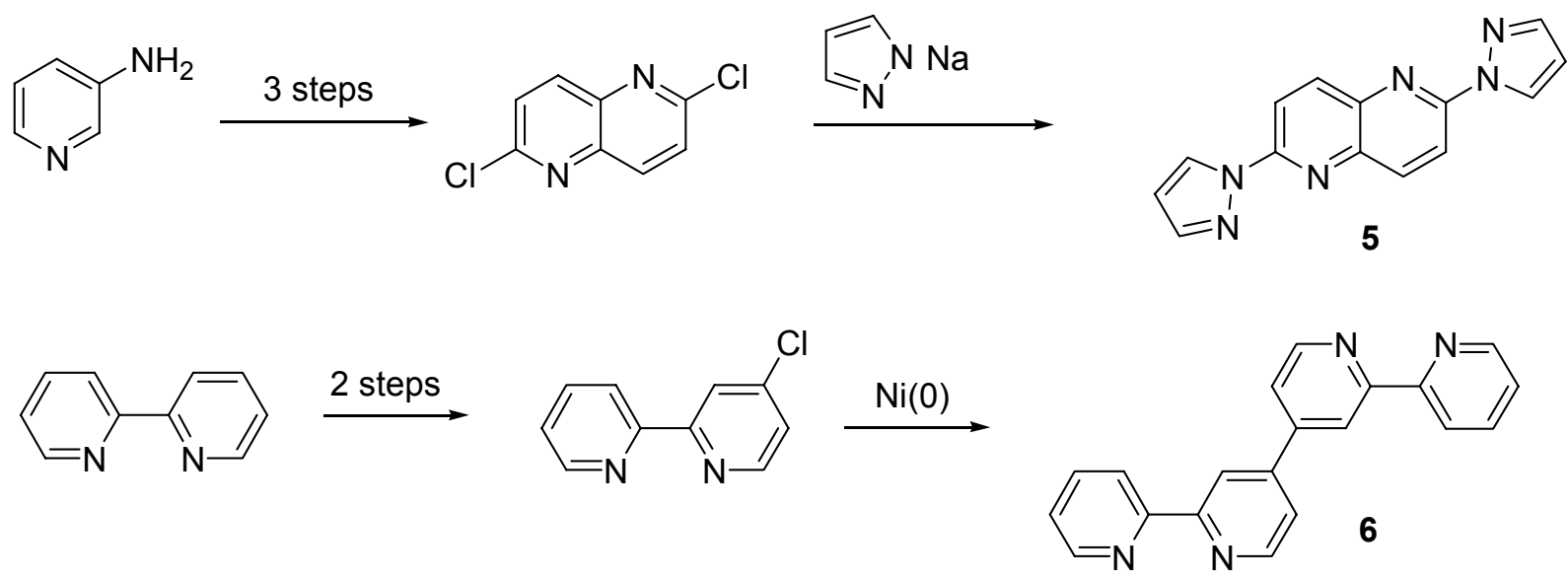

The dipyridylpyrimidine $\mathbf{4}$ was readily prepared by two sequential condensation reactions, starting from methyl picolinate and 2-acetylpyridine [10]. The 1,5-naphthyridine $\mathbf{5}$ was prepared by nucleophilic substitution of the dichloro precursor using sodium pyrazolate [11]. The quaterpyridine 6 was made by nickel(0)-mediated homocoupling of 4-chloro-2,2'-bipyridine [12]. Cyclic voltammetry of dinuclear ruthenium complexes of ligands 4-6 revealed a progressive reduction in the metal-metal interactions within the series, as the metals move further apart.

\section{Cyclometallated Analogues}

Replacement of one of the N-donors of such ligands by a carbon atom leads to $\mathrm{C}$, N-chelating systems that represent the interface between organometallic and coordination chemistry [13]. We have studied many such cyclometallated compounds, with particular emphasis on cyclopalladation reactions and the complete assignment of ${ }^{1} \mathrm{H}$ and ${ }^{13} \mathrm{C}$ NMR spectra of C,N-chelating cyclopalladated compounds $[14,15]$. We have extended this to the study of doubly cyclopalladated compounds, such as 7 and 8 (Scheme 3), which represent carbon analogues of the binucleating ligands 4 and 6 , respectively. These ligands were made by analogous procedures to those described above, but with phenyl rings replacing two of the pyridine rings [16,17]. Such doubly metallated compounds have also been shown to assemble into unusual box-like structures [18,19] and more recently to act as metallomesogens [20]. We have recently extended this to the synthesis of the first compound (9) containing a triply palladated benzene ring [21]. 


\section{Scheme 3.}

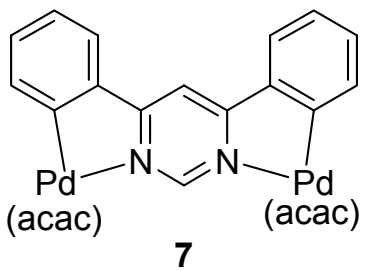
7

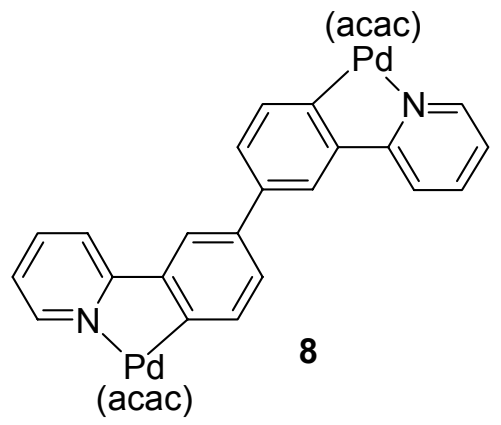

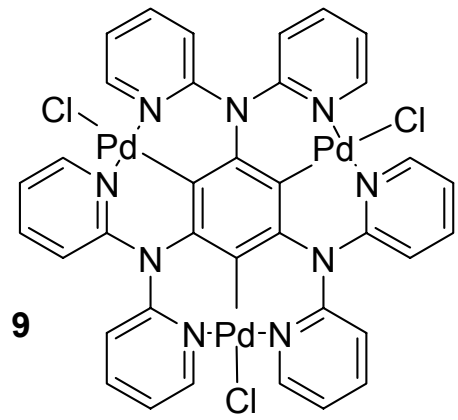

\section{Chiral Ligands}

Chiral N,N'-bidentate ligands are extensively employed in asymmetric synthesis as chiral auxiliaries. For example, metal complexes of $\mathrm{C}_{2}$-symmetric chiral bis-oxazoline ligands have found numerous applications as catalysts for a diverse range of organic reactions [22]. These ligands use the conformationally free side chains of amino acids to differentiate the faces of the oxazoline rings. We have synthesized numerous chiral ligands that incorporate a rigid bornane unit, derived from natural camphor, fused to various heterocycles, such as pyrazole, pyrazine and pyrimidine. von Zelewsky and co-workers have described many related ligands containing fused pinane units [23]. The syntheses of some representative examples are shown in Scheme 4.

\section{Scheme 4.}

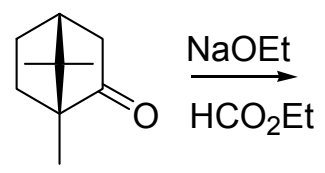

10

(i) $\mathrm{Na}, \mathrm{AmNO}_{2}$

(ii) $\mathrm{Zn}, \mathrm{AcOH}$

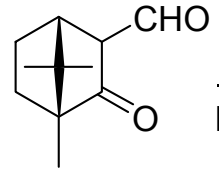

11

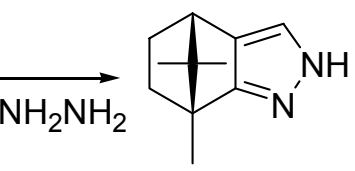

12

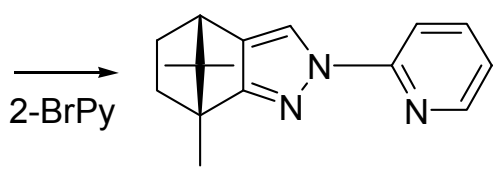

13

(i) $\mathrm{HNC}\left(\mathrm{NH}_{2}\right)_{2}$

(ii) $\mathrm{NaNO}_{2} / \mathrm{HCl}$

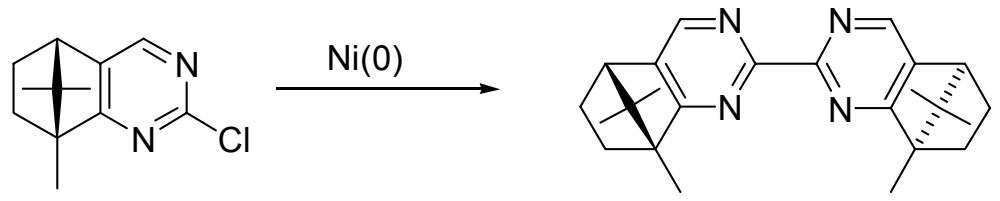

14

15

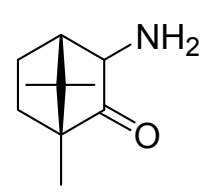

16

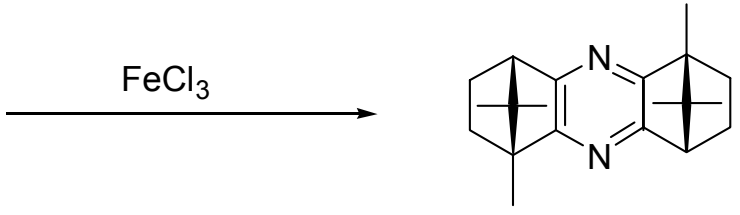

17 
Formylation of camphor (10) gave the 1,3-dicarbonyl compound 11, which was condensed with hydrazine to give the chiral pyrazole 12. This, in turn, was used to prepare a range of bidentate ligands, such as 13 [24], as well as tridentate [25,26], tripodal [27] and binucleating [27] ligands. Intermediate 11 was also condensed with guanidine, the resulting amine diazotized to give $\mathbf{1 4}$ which was subjected to nickel(0)-mediated coupling to prepare the $\mathrm{C}_{2}$-symmetric chiral bipyrimidine 15 [28]. Amination of camphor gave the derivative 16, which underwent oxidative dimerization to the $\mathrm{C}_{2}$-symmetric chiral pyrazine 17, which was used for the construction of chiral coordination polymers [29].

\section{Polyheteroaryl-linked Arenes}

We have synthesized a large family of ligands represented by the generalized structure 18 (Figure 1). These consist of a central arene core to which is appended a number ( $\mathrm{n}$ ) of heterocyclic N-donor rings attached via a spacer group $(\mathrm{X})$ of variable length. Changing the arene core, the type of heterocycle, the spacer and the number (n) of arms, allows access to a library of ligands that we have used for the formation of both discrete multinuclear molecular species and extended coordination polymers.

\section{Figure 1.}

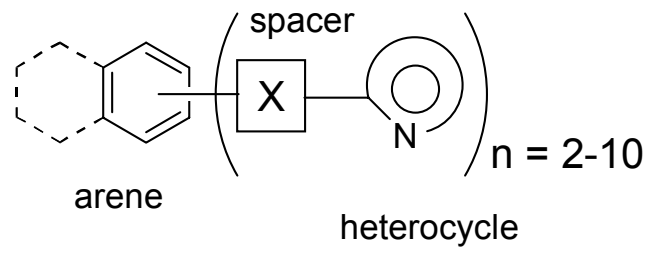

18

As arene cores we have employed benzenes, naphthalenes, biphenyls, binaphthyls, biphenylenes and triphenylenes. The spacer groups have been single atom linkers $\left(\mathrm{O}, \mathrm{NH}, \mathrm{CO}, \mathrm{CH}_{2}, \mathrm{~S}\right.$, etc), two atom linkers $\left(\mathrm{CH}_{2} \mathrm{O}, \mathrm{CH}_{2} \mathrm{~S}, \mathrm{CH}=\mathrm{CH}, \mathrm{N}=\mathrm{N}\right.$, etc), three atom $\left(\mathrm{CH}_{2} \mathrm{CH}_{2} \mathrm{CH}_{2}, \mathrm{CH}_{2} \mathrm{OCH}_{2}\right.$, etc) or longer. The heterocycles incorporated include both azines (pyridines, quinolines, etc) and azoles (pyrazoles, imidazoles, tetrazoles, benzotriazoles, etc). Variation in the number $\mathrm{n}$ between 2 and 10 has been employed.

The syntheses of five representative examples are shown in Scheme 5. The first of these (19) contains a benzene core, with three pyrazole donors attached via methylene linkers. The three ethyl substituents serve to pre-organize the substituents on alternating faces of the benzene ring [30]. It was prepared from commercially available 1,3,5-triethylbenzene by triple bromomethylation, followed by nucleophilic substitution with pyrazolate anion and used to prepare one of the first adamantanoid $\mathrm{M}_{6} \mathrm{~L}_{4}$ molecular cages [31]. Related ligands were also used to prepare a new class of compounds called cœlenterands [32]. 
Scheme 5.
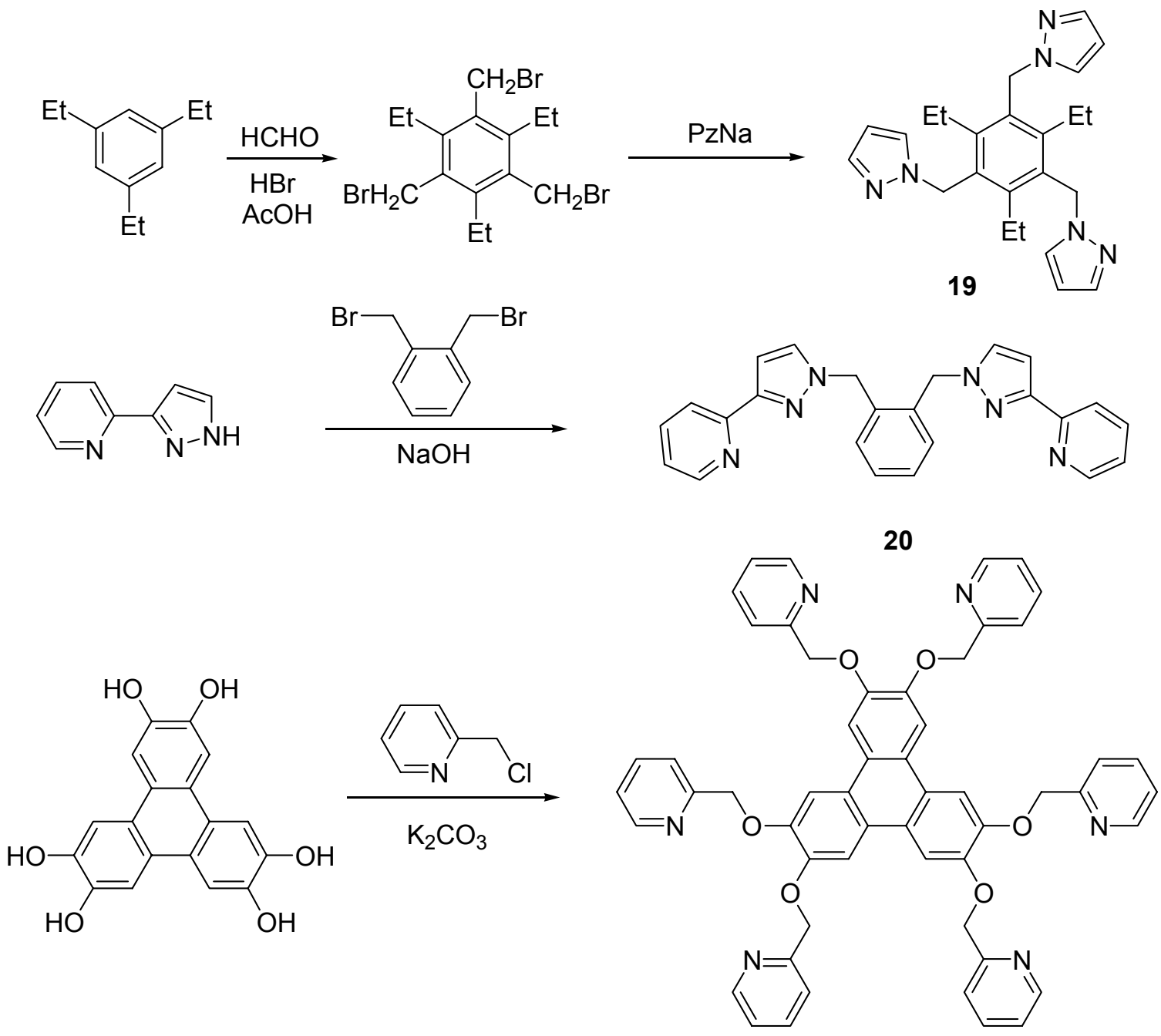

21<smiles></smiles>

22

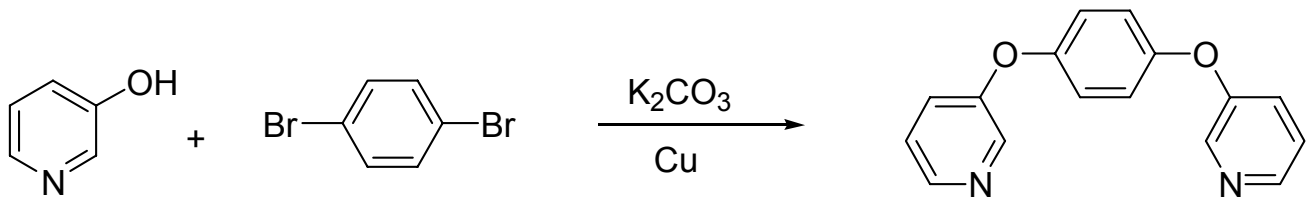


The second example (20) has an ortho-xylylene unit attached to two N,N'-chelating subunits and was prepared from 3-(2-pyridyl)pyrazole and 1,2-bis(bromomethyl)benzene, as shown. Upon reaction with silver nitrate it self-assembled into a novel trinuclear complex containing a linear $\mathrm{Ag}_{3}$ array [33]. The third example (21) consists of a triphenylene core with six 2-pyridyl substituents attached through two atom $\left(\mathrm{OCH}_{2}\right)$ linkers. It was prepared as shown and forms binuclear and trinuclear copper complexes [34].

Helicates are some of the most well studied metallosupramolecular assemblies [35,36]. The fourth ligand (22) has two benzotriazole donors attached via methylene spacers to a meta-substituted benzene ring. It was prepared by alkylation of benzotriazole with 1,3-bis(bromomethyl)benzene and formed a novel triple-stranded helicate upon reaction with silver nitrate [37]. Finally, the very simple ligand 23, which is readily prepared from para-dibromobenzene and 3-hydroxypyridine, has been used to prepare the first example of a quadruple-stranded helicate [38].

\section{Conclusions}

The five classes of ligands described above represent a diverse range of ligands that are readily prepared from commercially available starting materials in short synthetic sequences. Their reactions, with appropriate transition metal reagents, lead to a fascinating array of discrete or polymeric metallosupramolecular architectures, in highly efficient self-assembly processes.

\section{Acknowledgements}

The author wishes to thank the many talented co-workers who have made this work possible and

whose names appear in the references cited below and the organizers of the $25^{\text {th }}$ RACI-Melbourne Annual Synthesis Symposium for the invitation to present this paper.

\section{References}

1. Blau, F. Die destillation pyridinmonocarbonsaurer salze. Chem. Ber. 1888, 21, 1077-1078.

2. Constable, E. C. Homoleptic complexes of 2,2'-bipyridine. Adv. Inorg. Chem. 1989, 34, 1-63.

3. Constable, E. C.; Steel, P. J. N,N'-Chelating biheteroaromatic ligands; a survey. Coord. Chem. Rev. 1989, 93, 205-223.

4. Richardson, C.; Steel, P. J. Benzotriazole as a structural component in chelating and bridging heterocyclic ligands; ruthenium, palladium, copper and silver complexes. J. Chem. Soc., Dalton Trans. 2003, 992-1000.

5. Richardson, C.; Steel, P. J. Unpublished results, 2000.

6. Steel, P. J. Aromatic nitrogen heterocycles as bridging ligands; a survey. Coord. Chem. Rev. 1990, 106, 227-265.

7. Kaes, C.; Katz, A.; Hosseini, M. W. Bipyridine: the most widely used ligand. A review of molecules comprising at least two 2,2'-bipyridine units. Chem. Rev. 2000, 100, 3553-3590. 
8. Gavrilova, A. L.; Bosnich, B. Principles of mononucleating and binucleating ligand design. Chem. Rev. 2004, 104, 349-383.

9. Balzani, V.; Juris, A.; Venturi, M.; Campagna, S.; Serroni, S. Luminescent and redox-active polynuclear transition metal complexes. Chem. Rev. 1996, 96, 759-833.

10. Phillips, I. G.; Steel, P. J. Mono- and bi-nuclear complexes of the doubly bidentate, bridging ligand 4,6-di(2-pyridyl)pyrimidine. Aust. J. Chem. 1998, 51, 371-382.

11. Phillips, I. G. Syntheses and complexes of heterocyclic ligands. Ph.D. Thesis, University of Canterbury, 1995.

12. Downard, A. J.; Honey, G. E.; Phillips, L. F.; Steel, P. J. Synthesis and properties of a tris(2,2'bipyridine)ruthenium(II) dimer directly coupled at the C4 carbon. Inorg. Chem. 1991, 30, 22592260.

13. Constable, E. C. Cyclometallated complexes incorporating a heterocyclic donor atom; the interface of coordination chemistry and organometallic chemistry. Polyhedron 1984, 3, 10371057.

14. Steel, P. J.; Caygill, G. B. Cyclometallated compounds. II. Proton and carbon-13 nuclear magnetic resonance spectral assignments of cyclopalladated compounds. J. Organomet. Chem. 1987, 327, 101-114.

15. de Geest, D. J.; O'Keefe, B. J.; Steel, P. J. Cyclometallated compounds. XIII. Cyclopalladation of 2-phenoxypyridine and structurally-related compounds. J. Organomet. Chem. 1999, 579, 97-105.

16. Caygill, G. B.; Hartshorn, R. M.; Steel, P. J. Cyclometallated compounds. IV. Cyclopalladation of phenyl pyrimidines and X-ray structure of a doubly cyclopalladated derivative of 4,6diphenylpyrimidine. J. Organomet. Chem. 1990, 382, 455-469.

17. de Geest, D. J.; Steel, P. J. Cyclometallated compounds. XII. Syntheses of two new doublycyclometallated compounds. Inorg. Chem. Commun. 1998, 1, 358-360.

18. O'Keefe, B. J.; Steel, P. J. Cyclometallated compounds. XV. A tetranuclear, acetate-bridged, cyclopalladated molecular box. Acta Crystallogr. 2000, C56, 1440-1441.

19. O'Keefe, B. J.; Steel, P. J. Cyclometallated compounds. XVI. Double cyclopalladations of bis(2pyridyloxy)naphthalenes. Kinetic versus thermodynamic control over regioselectivity. Organometallics 2003, 22, 1281-1292.

20. Slater, J. W.; Lydon, D. P.; Rourke, J. P. Doubly cyclopalladated pyridazines: chiral liquid crystals. J. Organomet. Chem. 2002, 645, 246-255.

21. Sumby, C. J.; Steel, P. J. Cyclometallated compounds. XVII. The first three-fold cyclopalladation of a single benzene ring. Organometallics 2003, 22, 2358-2360.

22. Ghosh, A. K.; Mathivanan, P.; Cappiello, J. C2-symmetric chiral bis(oxazoline)-metal complexes in catalytic asymmetric synthesis. Tetrahedron: Asymmetry 1998, 9, 1-45.

23. Mamula, O; von Zelewsky, A. Supramolecular coordination compounds with chiral pyridine and polypyridine ligands derived from terpenes. Coord. Chem. Rev. 2003, 242, 87-95.

24. Steel, P. J. Dichloro[(4S,7R)-7,8,8-trimethyl-2-(2-pyridyl)-4,5,6,7-tetrahydro-4,7-methano-2Hindazole]palladium(II), $\mathrm{C}_{16} \mathrm{H}_{19} \mathrm{Cl}_{2} \mathrm{~N}_{3} \mathrm{Pd}$. Acta Crystallogr. 1983, C39, 1623-1625. 
25. House, D. A.; Steel, P. J.; Watson, A. A. Chiral heterocyclic ligands. IV. Synthesis and metal complexes of 2,6-bis(pyrazol-1-ylmethyl)-pyridine and chiral derivatives. Inorg. Chim. Acta 1987, 130, 167-176.

26. Watson, A. A.; House, D. A.; Steel, P. J. Chiral heterocyclic ligands. VII. Syntheses of some chiral 2,6-bis(N-pyrazolyl)pyridines. J. Org. Chem. 1991, 56, 4072-4074.

27. Watson, A. A.; House, D. A.; Steel, P. J. Chiral heterocyclic ligands. VIII. Syntheses and complexes of new chelating ligands derived from camphor. Aust. J. Chem. 1995, 48, 1549-1572.

28. Downard, A. J.; Phillips, I. G.; Steel. P. J. Chiral heterocyclic ligands. X. Synthesis and metal complexes of hindered and chiral 2,2'-bipyrimidines. Aust. J. Chem. submitted for publication.

29. Fitchett, C. M.; Steel, P. J. Chiral heterocyclic ligands. Part 9. Homoconfigurational coordination polymers based on a $\mathrm{C}_{2}$-symmetric, linear-bridging ligand. New J. Chem. 2000, 24, 945-947.

30. Hennrich, G.; Anslyn, E. V. 1,3,5-2,4,6-Functionalized, facially segregated benzenes exploitation of sterically predisposed systems in supramolecular chemistry. Chem. Eur. J. 2002, 8, 2218-2224.

31. Hartshorn, C. M.; Steel, P. J. Self-assembly and X-ray structure of a ten-component, threedimensional, metallosupramolecular cage. Chem. Commun. 1997, 541-542.

32. Hartshorn, C. M.; Steel, P. J. Coelenterands: a new class of metal-encapsulating ligands. Angew. Chem., Int. Ed. Engl. 1996, 35, 2655-2657.

33. Hartshorn, C. M.; Steel, P. J. Bis(3-(2-pyridyl)pyrazol-1-ylmethyl)benzenes, doubly-chelating binucleating ligands and encapsulation of a linear trisilver(I) moiety. Inorg. Chem. Commun. 2000, 3, 476-481.

34. O'Keefe, B. J. Synthesis and complexes of heterocyclic ligands. Ph.D. Thesis, University of Canterbury, 1999.

35. Piguet, C.; Bernardinelli, G.; Hopfgartner, G. Helicates as versatile supramolecular complexes. Chem. Rev. 1997, 97, 2005-2062.

36. Albrecht, M. "Let's twist again"-double-stranded, triple-stranded, and circular helicates. Chem. Rev. 2001, 101, 3457-3497.

37. O'Keefe, B. J.; Steel, P. J. Self-assembly and X-ray structure of a triple helicate with two trigonal silver(I) termini. Inorg Chem. Commun. 2000, 3, 473-475.

38. McMorran, D. A.; Steel, P. J. The first coordinatively-saturated quadruply-stranded helicate and its encapsulation of a hexafluorophosphate anion. Angew. Chem., Int. Ed. 1998, 37, 3295-3297.

(C) 2004 by MDPI (http://www.mdpi.org). Reproduction is permitted for noncommercial purposes. 